\title{
Research on the Application of Right Brain Thinking in the Innovation of Architectural Design Teaching Method
}

\author{
Lei Zhang ${ }^{1}$ \\ Chang'an University
}

\author{
Jingyuan Zhao ${ }^{2}$ \\ Chang'an University
}

\author{
Yun $\mathrm{Li}^{3}$ \\ Chang'an University
}

\begin{abstract}
Scientific cognition of the brain helps students improve their design thinking abilities. This paper attempts to study the application of the right-brain development philosophy in the architectural design teaching. By using the literature analysis, case analysis and comparative analysis methods, based on the theoretical research results of brain-science-based education and right-brain thinking development at home and abroad, this paper analyzes the specific relationship between the right-brain thinking and the architecture design, and considering the issues in the current architectural design discipline, it constructs a theoretical teaching framework based on the rightbrain development philosophy, designs a teaching program based on right-brain thinking according to the course content of architectural design. Then this paper compares and analyze the teaching effects in actual teaching activities, hoping to provide some new reference and basis for architectural design teaching.
\end{abstract}

\section{Keywords}

Right-Brain Development $・$ Right-Brain Thinking $•$ Architectural Design $\bullet$ Teaching Method

\footnotetext{
This work was supported by Programs for Science and Technology Development of Henan science and Technology Department(15102310026): Research on the spatial optimization strategy of immigrant village.

${ }^{1}$ Correspondence to: Lei Zhang. School of Architecture, Chang'an University, Xi'an 710061, China. Email: zl.wc@qq.com

${ }^{2}$ School of Architecture, Chang'an University, Xi'an 710061, China. Email: $\underline{845725427 @ q q . c o m}$

${ }^{3}$ School of Architecture, Chang'an University, Xi'an 710061, China. Email: liyun@ chd.edu.cn

Citation: Zhang, L., Zhao, J. Y., Li, Y. (2018). Research on the Application of Right Brain Thinking in the Innovation of Architectural Design Teaching Method. Educational Sciences: Theory \& Practice, 18(5), 2009-2018. http://dx.doi.org/10.12738/estp.2018.5.100
} 
Zhang, Zhao, Li, / Research on the Application of Right Brain Thinking in the Innovation of Architectural Design ...

The brain is the main tool for people to receive knowledge and conduct learning. In the 21st century, known as "the era of brain", the brain-based education science brought new opportunities and challenges to the education reform and innovation. Many scholars have been keen to study the specificity of the right-brain thinking function. Through the "split brain" experiment, Roger Wolcott Sperry proposed the theory that the right brain is the art brain or creative brain, emphasizing the particularity of the right brain in terms of function (Blakemore, 2010). Later, researchers proposed the right brain have special roles in cognitive aspects, including image, vision and information processing (Ballonoff et al., 2015). Domestic studies on right-brain thinking are all based on foreign theories, and the research results are rather limited. According to the books Right Brain Potential Development Techniques and Right Brain Storm, the development of the right-brain thinking potential is of great significance to the mankind (Ivanovic et al., 2014). Its significance to education is one of the key subjects of domestic research. The researchers are working on the advantages of the right brain in cognitive and creative thinking (Cardoza, 2011).

With the advent of globalization, the construction market and architecture education in China are facing unprecedented challenges. The traditional experience-based teaching model can no longer meet the increasingly diversified and open market demands. Through surveys, it is found that currently there is an imbalance between theory and practice in architectural education. The design thinking relies too much on experience and the design works are conceptualized. The students lack the awareness of innovation and teachers lack diversified thinking teaching methods (Mehravari, Emmorey, Prat, Klarman, \& Osterhout, 2017). In order to cultivate interdisciplinary talents that can meet the needs of the society, the architecture education in China should be reformed in teaching ideas and methods, focus on cultivating rational design thinking and establish innovative and characteristic educational systems and teaching methods.

Based on the above analysis, this paper attempts to study the architectural design teaching method from the perspective of right-brain thinking based on the research results of brain science. Through the introduction of the right-brain thinking and right-brain development theories, it seeks for the relationship between right-brain thinking development and architectural design. Based on the natural learning system of the brain, this paper constructs a theoretical teaching framework based on the right-brain development philosophy and designs a teaching program for the architectural design course based on right-brain thinking. By taking the exercise kindergarten design in the architectural design course as an example, this paper analyzes the teaching effects on architectural design and also the questionnaire survey results of teachers and students. The results prove that the application of right-brain thinking in the teaching of architectural design has a certain positive effect in promoting students' learning and creation work and also provides a new reference to some extent for the innovation and practice of architectural design teaching.

\section{Theoretical foundation for right-brain thinking}

\section{The theory of "right-brain thinking"}

The activities of the cerebral cortex enable human to think and learn. The left and right hemispheres of the brain have different functions: the left brain has advantages in logical thinking, while the right brain is good at perceptual thinking, as shown in Fig. 1 (Restaino, 2011). For a long time, educators have only focused on the 
Zhang, Zhao, Li, / Research on the Application of Right Brain Thinking in the Innovation of Architectural Design ...

development and utilization of the left brain and developed students' logical thinking abilities, but few efforts have been made to develop their perceptual and imaginal thinking in music, sports and art (Ledewitz, 1985).

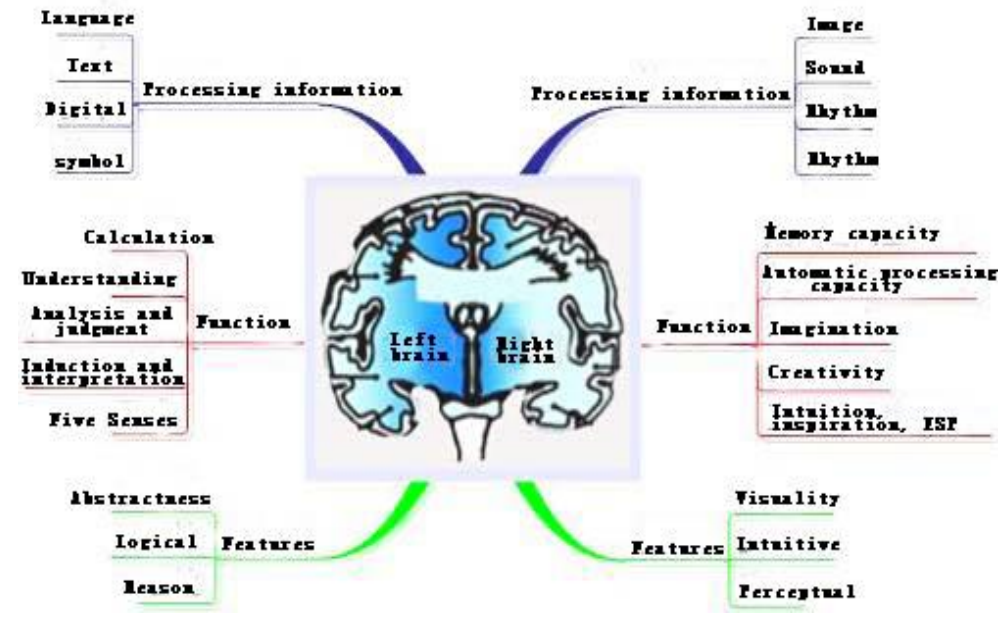

Figure 1. Left and right brain function diagram

\section{Development of "right-brain thinking"}

Thinking activities vary with the different structures of the human brains, but for most people, the left-brain functions have been well developed and exercised, while the right brain - the hemisphere that is responsible for non-logical thinking - still has a lot of potential yet to be exploited (Tice, 1993). The right-brain thinking is a direct response of human consciousness. The right hemisphere can receive information intuitively and have special preference for perceptual, non-logical, visual, artistic and creative thinking, and thus it is highly plastic and innovative (West, 2001). The application of right-brain thinking in teaching can help promote the overall healthy development of the human brain, which meets the basic requirement for quality education, and the development of right-brain thinking should be conducted on the premise that the left and right brain functions are coordinated. Fig. 2 shows the teaching based on right-brain thinking is carried out in three forms - classroom, life-oriented, and assisted teaching (Gürel \& Potthoff, 2006).

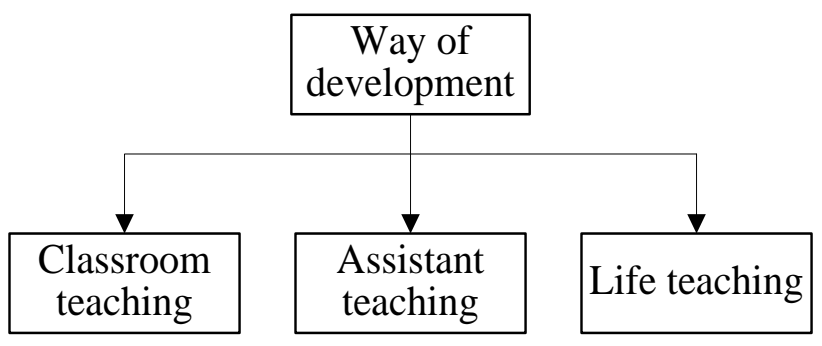

Figure 2. "Right brain thinking" teaching method 


\section{Architectural design teaching design and implementation based on right-brain thinking}

\section{Elements of right-brain thinking related to architectural design teaching}

Related theories. Table 1 shows the right-brain thinking theories related to the architectural design teaching and the practice method for thinking training (Soygenis et al., 2010).

(1) Cognitive theory

Intuition is indispensable in architectural design as it can help people abstract and associate things, and rightbrain thinking enables people to know things and form an intuitive understanding of them, i.e. intuitions (Andia, 2002). Students studying architectural design need to have better perception and understanding of things, so right-brain thinking is very important in architectural design teaching.

(2) Design science

Right-brain thinking can intuitively reflect people's thoughts and is a manifestation of their personalities. So in architecture design, right-brain thinking can help people better understand the relationships between themselves and their works.

(3) Philosophical thinking

Right-brain thinking is the process from material to consciousness. In essence, "things" are always the origins of architectural design, and through the designer's thinking, they are finally transformed into design works. This process from the origin to the derivative fully embodies the philosophy "material determines consciousness".

(4) Aesthetics

In architectural design, the understanding of beauty is a process from perceptual thinking to rational thinking. The perceptual thinking that the right brain is good at is the main way people judge whether something is beautiful or not. In this process, there is no rational thinking. But the unity of perception and rationality is the goal that architects should all pursue.

Table 1

Right-brain Thinking and Related Theories

\begin{tabular}{|c|c|c|c|c|}
\hline \multirow{2}{*}{$\begin{array}{l}\text { Subject } \\
\text { Cognitive }\end{array}$} & \multicolumn{2}{|c|}{ The starting point and way of thinking } & \multicolumn{2}{|c|}{ The end of the way of thinking } \\
\hline & Cognitive & Intuition & Cognitive & Perception \\
\hline Design & Personality & Image & Creativity & Innovation \\
\hline Philosophy & Origin & Non-logical & Derivative & Logic \\
\hline Aesthetics & Soul & Perceptual & Review & Reason \\
\hline
\end{tabular}

Interactions in teaching practice. The brain's learning system reveals that the genetic factor and the external environment are the two main factors affecting brain learning. Table 2 shows the five elements of the brain's natural learning system and their relationships with each other (Chiang, 2015). The brain's learning system theory effectively guides the element analysis of the personality awareness strengthening in right-brain thinking, elaborates the role of teacher and the needs of students in the learning process, and provides reference 
Zhang, Zhao, Li, / Research on the Application of Right Brain Thinking in the Innovation of Architectural Design ...

and basis for how to apply right-brain thinking in architectural design teaching.

Table 2

Natural Learning System Elements of the Brain

\begin{tabular}{llll}
\hline Major factor & Core content & The role of teachers & \multicolumn{1}{c}{ Student needs } \\
\hline Emotional learning & Passion & Mentor and Model & Personal advantage is respected \\
Social learning & Cooperation & Collaborators & A sense of belonging \\
Cognitive learning & Purpose & Promoters & Seek knowledge \\
Physical learning & Action & Coach & Which performed \\
Reflection learning & Reflection & Talent explorers & Self-monitoring and growth \\
\hline
\end{tabular}

\section{Design and implementation of the architectural design teaching program based on right-brain thinking}

Teaching program design. The teaching program based on right-brain thinking is designed in a way that is in line with the brain thinking pattern to meet the basic requirements for cultivation of architects. The purpose is to use multiple stimuli to develop right-brain thinking skills and balance the left and right brain functions so as to enable a complete and reasonable thinking process. In this paper, the teaching program is designed from the following three aspects: guiding the right-brain thinking by changing the thinking direction, improving the thinking process by changing the thinking time and optimizing the cognitive approach by changing the thinking position, as shown in Table 3 (Shannon, Francis, Chooi, \& Ng, 2013).

(1) Guiding the right-brain thinking by changing the thinking direction

Changing the thinking direction means guiding students to break the mono-thinking mode and encourage them to think reversely and individually. In teaching, the teacher should encourage students to discard the influences of existing resources on themselves and use their right brains to form the first impression and achieve personalized thinking and ask students to analyze and solve the same problem from different perspectives.

Table 3

Right-brain-thinking teaching program design

\begin{tabular}{|c|c|c|c|}
\hline Method & Content & For objects & Purpose \\
\hline $\begin{array}{l}\text { Change } \\
\text { direction }\end{array}$ & $\begin{array}{l}\text { Start with blank } \\
\text { Converse to } \\
\text { experience }\end{array}$ & $\begin{array}{l}\text { Order of thinking } \\
\text { Habit of thinking }\end{array}$ & $\begin{array}{l}\text { Change the mindset to find the right } \\
\text { brain sensibility }\end{array}$ \\
\hline $\begin{array}{l}\text { Change } \\
\text { time }\end{array}$ & $\begin{array}{l}\text { Thinking fast } \\
\text { Time and space }\end{array}$ & $\begin{array}{l}\text { Thinking time } \\
\text { Time space }\end{array}$ & $\begin{array}{l}\text { Stimulate right brain intuition and } \\
\text { grasp general characteristics }\end{array}$ \\
\hline $\begin{array}{l}\text { Change } \\
\text { position }\end{array}$ & $\begin{array}{l}\text { Ectopic observation } \\
\text { Open space } \\
\text { Moving image } \\
\text { Special fit }\end{array}$ & $\begin{array}{l}\text { Author's perspective } \\
\text { Environmental perspective } \\
\text { Object angle } \\
\text { Relationships }\end{array}$ & $\begin{array}{l}\text { Rethinking things from a new } \\
\text { perspective and stimulating right } \\
\text { brain activity with strangeness }\end{array}$ \\
\hline
\end{tabular}

Improving the thinking process by changing the thinking time. (1) Training of quick-thinking questions

The process where the brain cognize things depends on how long the brain perceives these things. Shortening the stimulation time of the things to the brain helps reduce the logical thinking in the left brain and develop the right-brain thinking. The purpose of the quick question training is to allow the designers to complete the design tasks in a relaxed state. It does not require the integrity of the design but seeks to reserve the designer's intuitions. 
Zhang, Zhao, Li, / Research on the Application of Right Brain Thinking in the Innovation of Architectural Design ...

(2) Space-time interleaving exercise

Space-time interleaving exercise means that the teacher should create conditions for students to fully understand things in different time and space instead of correcting students' feelings and personalities in designing with the inherent concepts. The specific approach is to recombine different things at different states. For example, when the same tree changes with the four seasons, it will present different visual effects to people (Bati, 2014).

Optimizing the cognitive approach by changing the thinking position. The brain thinking activities vary with the way of visual reading. The right-brain thinking plays a significant role in cognition. Therefore, this part of the teaching program attempts to change the information received by changing the positions of the observed and the observer so as to develop and train the right brain. The specific methods include "transpositional" observation method, open space method and expression fit method (Caglar \& Uludag, 2006). Fig. 3 shows a typical case of the expression fit approach, which stimulates students' vision through the interlacing of objects to train their right-brain thinking.

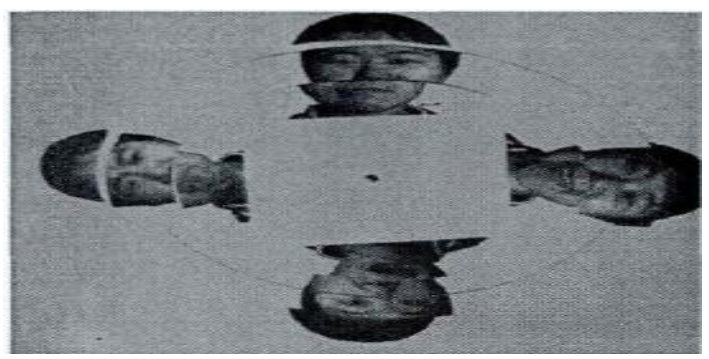

Figure 3. Expression fit

Implementation of the teaching program. In order to explore the effects of the right-brain thinking teaching method in practical teaching, this paper applies this method in the kindergarten design exercise in the second-grade architectural design course in the School of Architecture and compares and analyzes the implementation results of the architectural design teaching program based on right-brain thinking. Fig. 4 shows an analysis of the architectural design teaching based on right-brain thinking (Rawes, 2017).

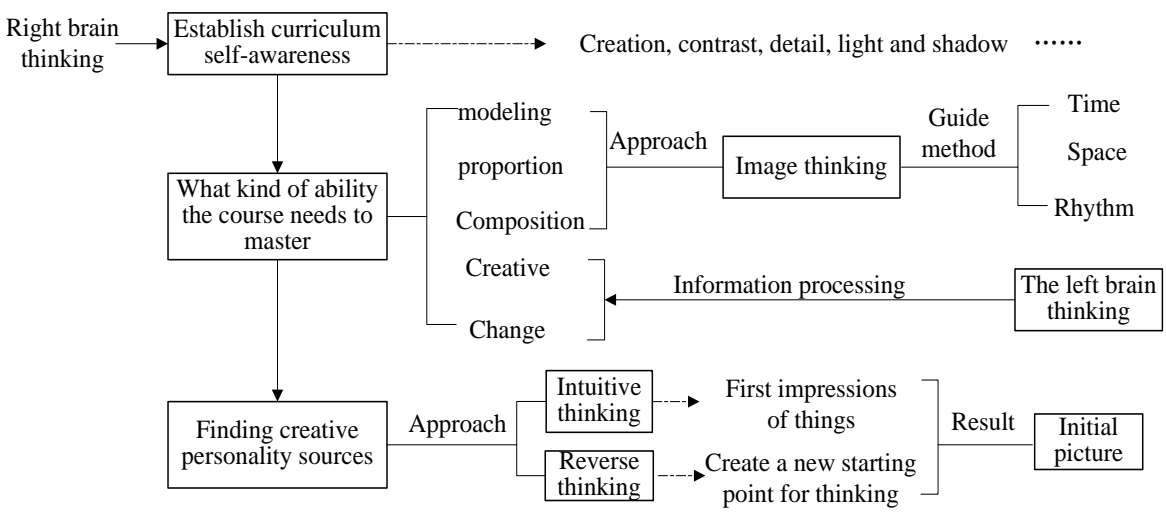

Figure 4. Analysis of the architectural design teaching based on right-brain thinking 
Zhang, Zhao, Li, / Research on the Application of Right Brain Thinking in the Innovation of Architectural Design ...

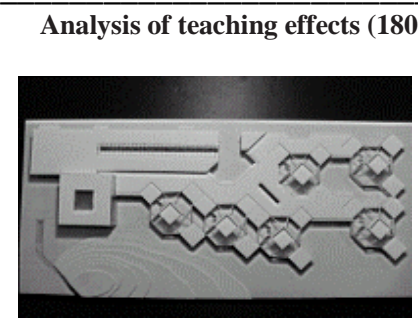

(1) Morphological relations of the architecture

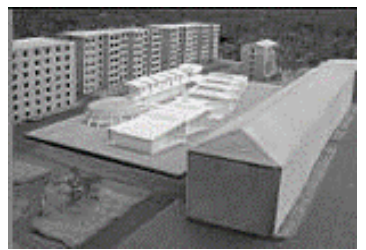

(2) Relations with the environment

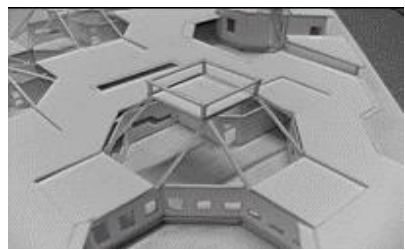

(3) Specific form of monomer structure

(a) Before the experiment

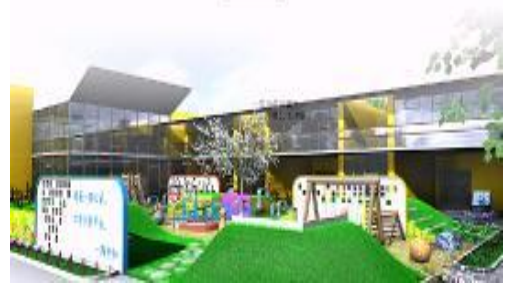

(1) Expression of outdoor venue

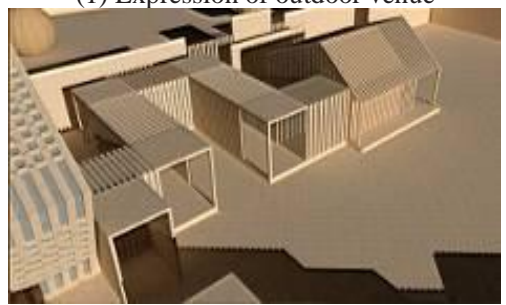

(3) Research on Traffic Space Gallery

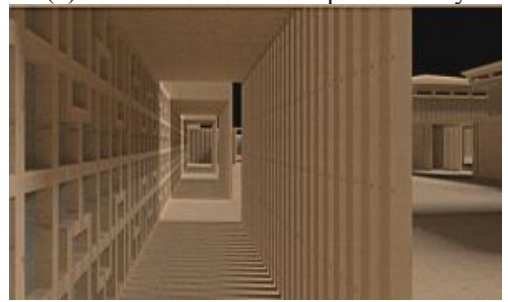

(5) Research on spatial interface form and degree of dimensionality

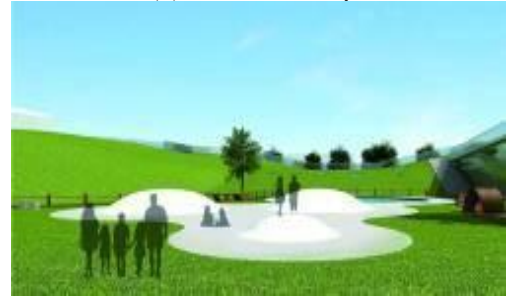

(6) Expression of the landscape environment, gaming facilities and behaviors outside the building

(b) After the experiment

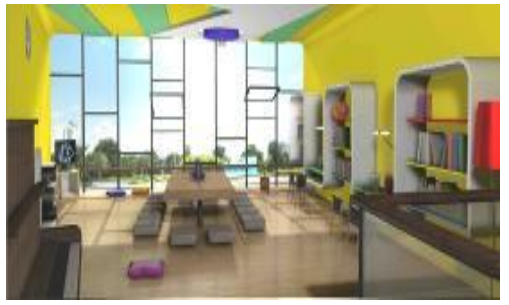

(2) Research on indoor color

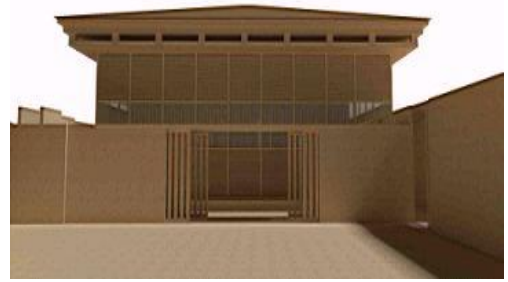

(4) Study on the monomer form and details
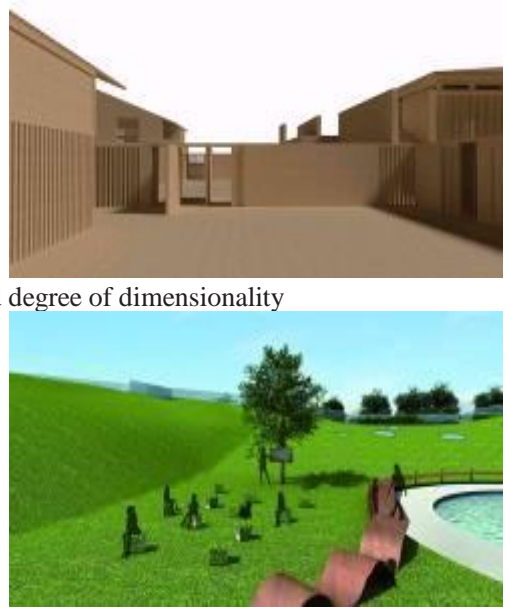

Figure 5. Kindergarten design models 
Fig. 5 compares the final design models of kindergarten before (a) and after (b) the teaching experiment. Before the right-brain thinking teaching experiment, the kindergarten design models mainly presented the morphological relations of the architecture, the relations with the environment and the specific form of monomer structure. After the experiment, the models studied and presented many aspects, including space, site, landscape, material, detail and light and shadow. After the experiment, students shifted their focus on the process and continuity of design thinking and emphasized the expression of design ideas rather than the expression of final design effects.

(2) Teachers' feedbacks on the design results

From the teachers' feedbacks on the design results of the experimental class (under the right-brain thinking teaching method) and control class in Fig.6, it can be seen that, the design results of the experimental class are generall better than those of the control class, especially in terms of design ideas, research depth and expression of thinking.

(3) Statistics of students' final design results

It can be seen from the statistics of the design results of the experimental class and control class in Fig. 7 that students in the experimental class who received the right-brain thinking teaching had an obvious advantage in the coherence of design thinking compared with those in the control class $-35 \%$ in the experimental class and $15 \%$ in the control class. In other aspects, including the outcome drawing, model expression and other design achievements like PPT, the experimental class also did much better than the control one.

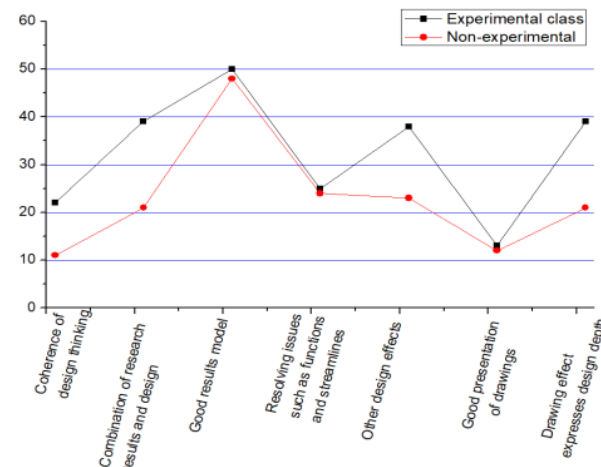

Figure 6. Teachers feedback on experimental and non-experimental class design results

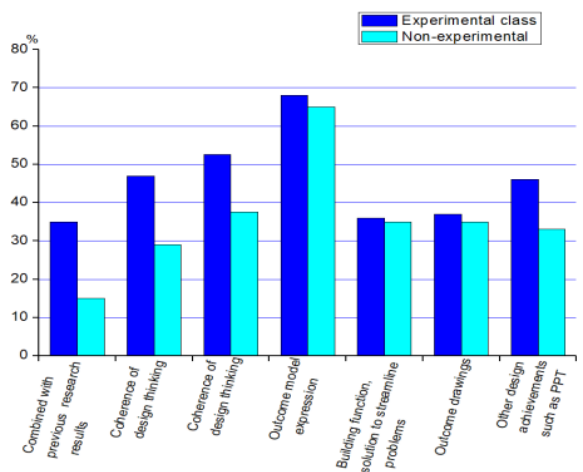

Figure 7. Experimental and non-experimental class design achievement statistics

\section{Conclusions}

With the application of the right-brain development philosophy in the architectural design teaching method as the object, this paper reviews the related literatures at home and abroad and analyzes the specific relationships between right-brain thinking and architectural design teaching. The following conclusions are obtained:

(1) Theoretically, this paper constructs a theoretical teaching framework based on right-brain thinking and 
Zhang, Zhao, Li, / Research on the Application of Right Brain Thinking in the Innovation of Architectural Design ...

related theories.

(2) Based on the theoretical right-brain thinking teaching framework, this paper designs and analyzes the teaching program based on right-brain thinking according to the content of the architectural design course.

(3) This paper compares and analyzes the design results after the implementation of the teaching program and performs statistical analysis of the students' design results and the students' feedbacks on these results. The analysis shows that the teaching method based on right-brain thinking has some positive effects on students' learning and professional creation.

\section{Acknowledgement}

Programs for Science and Technology Development of Henan science and Technology Department(15102310026): Research on the spatial optimization strategy of immigrant village.

\section{References}

14. Shannon, S. J., Francis, R. L., Chooi, Y. L. \& Ng, S. L. (2013). Approaches to the use of blended learning in teaching tectonics of design to architecture/design and architectural engineering students. Architectural Science Review, 56(2), 131-140. http://dx.doi.org/10.1080/00038628.2012.744688

Andia, A. (2002). Internet studios: teaching architectural design on-line between the united states and latin america. Leonardo, 35(3), 297-302. http://dx.doi.org/10.1162/002409402760105316

Ballonoff, S. A., Johnson, M., Shirtcliff, E. A., \& Galván, A. (2015). School-based sex education and neuroscience: what we know about sex, romance, marriage, and adolescent brain development. Journal of School Health, 85(8), 567. http://dx.doi.org/10.1111/josh.12285

Bati, J. (2014). Implementing change in architectural design in elementary school art education in Slovenia. International Journal of Art \& Design Education, 33(1), 130-140. http://dx.doi.org/10.1111/j.14768070.2014.01741.x

Blakemore, S. J. (2010). The developing social brain: Implications for education. Neuron, 65(6), 744-7. http://dx.doi.org/10.1016/j.neuron.2010.03.004

Caglar, N., \& Uludag, Z. (2006). Architectural design education: designing a library, public communication and information center in the manufacturing zone of central Eskis, Ehir Turkey, a case study. International Journal of Art \& Design Education, 25(2), 231-240. http://dx.doi.org/10.1111/j.1476-8070.2006.00487.x

Cardoza, M. P. (2011). Neuroscience and simulation: an evolving theory of brain-based education. Clinical Simulation in Nursing, 7(6), e205-e208. http://dx.doi.org/10.1016/j.ecns.2011.08.004

Chiang, R. N. S. (2015). Teaching by team: Environmental technology (mechanical systems) as elements of architectural design. Journal of Architectural Education, 90(Supp 1), 29-30. http://dx.doi.org/10.1080/10464883.1974.11102530

Gürel, M. Ö., \& Potthoff, J. K. (2006). Interior design in architectural education. International Journal of Art \& Design Education, 25(2), 217-230. http://dx.doi.org/10.1111/j.1476-8070.2006.00486.x 
Zhang, Zhao, Li, / Research on the Application of Right Brain Thinking in the Innovation of Architectural Design ...

Ivanovic, D. M., Ibaceta, C. V., Correa, P. B., Orellana, Y. Z., Calderón, P. M., \& Morales, G. I. (2014). Brain development and scholastic achievement in the education quality measurement system tests in Chilean school-aged children. Pediatric Research, 75(3), 464-70. http://dx.doi.org/10.1038/pr.2013.232

Ledewitz, S. (1985). Models of design in studio teaching. Journal of Architectural Education (1984-), 38(2), 28. http://dx.doi.org/10.1080/10464883.1985.10758354

Mehravari, A. S., Emmorey, K., Prat, C. S., Klarman, L., \& Osterhout, L. (2017). Brain-based individual difference measures of reading skill in deaf and hearing adults. Neuropsychologia, 101, 153. http://dx.doi.org/10.1016/j.neuropsychologia.2017.05.004

Rawes, P. (2007). Reflective subjects in Kant and architectural design education. Journal of Aesthetic Education, 41(1), 74-89. http://dx.doi.org/10.1353/jae.2007.0006

Restaino, R. (2011). Gain attention, enhance memory, and improve learning with brain-based strategies. Journal of Continuing Education in Nursing, 42(5), 199. http://dx.doi.org/10.3928/00220124-20110421-04

Soygenis, S., Soygenis, M., \& Erktin, E. (2010). Writing as a tool in teaching sketching: Implications for architectural design education. International Journal of Art \& Design Education, 29(3), 283-293. http://dx.doi.org/10.1111/j.1476-8070.2010.01646.x

Tice, J. (1993). Theme and variations: A typological approach to housing design, teaching, and research. Journal of Architectural Education $\quad$ (1984-), $\quad 46(3), \quad$ 162-175. http://dx.doi.org/10.1080/10464883.1993.10734552

West, M. (2001). Construction-reseach-design-invention: Elastic behavior in a moist environment. Journal of Architectural Education, 54(4), 251-254. http://dx.doi.org/10.1162/10464880152474574 